\title{
Eighth International Conference on Mycorrhizas ICOM8
}

\section{Mycorrhizal integration across continents and scales}

\author{
August 3-7, 2015 \\ Northern Arizona University \\ Flagstaff, Arizona USA
}

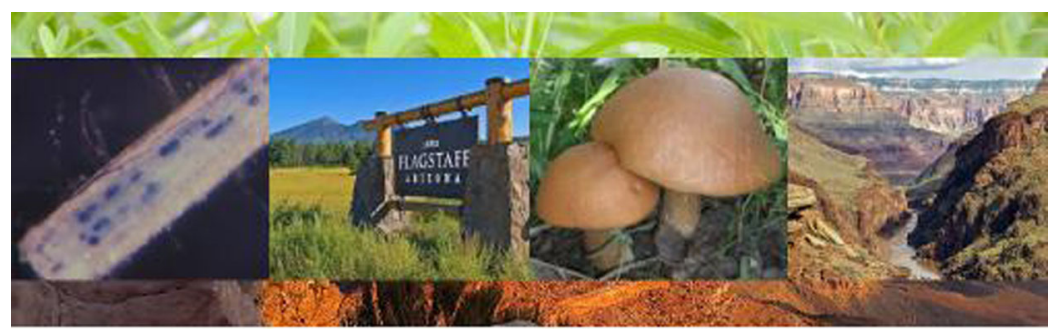

ICOM8: Mycorrhizal integration across continents and scales will provide a global perspective in sessions designed to cut across traditional scientific disciplines.

This theme reflects the broad interests of mycorrhiza researchers and users who work towards problem-based integration of natural sciences, from molecular genetics through physiology to ecosystem and landscape ecology.

An engaging scientific program and the many attractions near Flagstaff Arizona will make ICOM8 an inspiring meeting.

Please plan to attend!

Visit our site for more details: http://nau.edu/Merriam-Powell/ICOM8/

Co-organizers: Catherine Gehring (Catherine.Gehring@nau.edu) and Nancy Collins Johnson (Nancy.Johnson@nau.edu) 